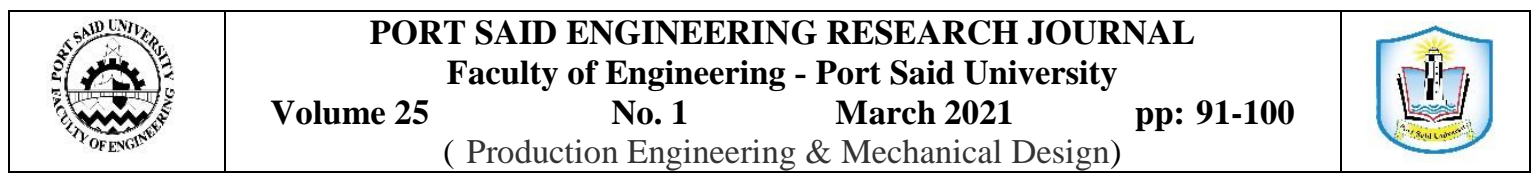

\title{
Optimization of Inertia Friction Welding of Dissimilar Polymeric PA6-PVC Hollow Cylinders by Genetic Algorithm
}

\author{
Elsanabary S. ${ }^{1}$, Kouta H. ${ }^{2}$ \\ Received: 24 June 2020; Accepted: 6 August 2020
}

\begin{abstract}
Three-dimensional elasto-plastic thermal-mechanical transient axisymmetric explicit finite element models were used to simulate the friction joining of hollow cylinder dissimilar polymeric materials PA6-PVC. The FE model takes into account the mechanical and thermal properties of PA6 and PVC as an input date. Also, the simulation analysis considered three independent variables namely, rotational speed of (500, 775, and $1200 \mathrm{rpm}$ ), axial displacement of $(0.045,0.09$, and $0.18 \mathrm{~mm})$, and total welding time of $(4,6$, and 8 seconds). With respect to the FE model, the regression model is built. The minimum and maximum error percentage between FE and predicted results by regression model of welding temperature are $0.08 \%$ and $17.26 \%$ respectively. On the other hand, the error percentages of Von Mises residual stress start from $0.34 \%$ to $26.15 \%$. The regression model is used to formulate the GA's fitness function for end welding temperature and Von Mises residual stresses. This paper showed that the GA technique is capable of estimating the optimum welding conditions that yield the value of the minimum end welding temperature and the Von Mises residual stresses relative to the results of FE and regression.
\end{abstract}

KEYWORDS : Inertia friction welding, Thermoplastics, Numerical Simulation, Regression model, Genetic Algorithm.

\section{INTRODUCTION}

Inertia Friction Welding (IFW) is a solid-state joining process capable of producing high-quality joints of similar and dissimilar materials $[1,7]$. In products where temperatures, stresses and life conditions are highly demanding, high-quality welds are required to fulfil the performance specifications. One of the advantages of IFW is the ability to welds materials that are difficult or impossible to weld with high-integrity. The fusion-welding techniques and the ease of the process can be controlled once the tool and welding for the process has been properly designed [8-10].

Some of the aims of using dissimilar joints are to improve the flexibility of product design so that the different components can be used effectively and reliably depending on the specific characteristics of each material [11]. Friction welding has been used for joining together dissimilar materials, including materials that are difficult to weld using traditional welding techniques.

${ }^{1}$ Lecturer in Production Eng., Faculty of Eng., Port Said University, email: samar.abaas@eng.psu.edu.eg

${ }^{2}$ Lecturer in Production Eng., Faculty of Eng., Port Said

University, email: Hanan.kamel@eng.psu.edu.eg

DOI: $10.21608 /$ pserj.2020.33683.1048
These may also join materials with substantially different metallurgical behaviors at or close the liquids and solid temperatures of the individual alloy [12]. Many problems occur during IFW of dissimilar metals because of the different hardness, melting temperature properties and the potential for surface interaction generating either brittle intermetallic phases or low eutectic melting points [13].

Over the past few years, the mechanical behavior of engineering thermoplastics has gained growing attention. Thermoplastics are classified into amorphous and semi-crystalline thermoplastics, such as PVC and PA6 respectively. One explanation for this attention in thermoplastic's engineering is the growing number of applications in several fields, including automotive components such as instrument panels, radiator fans, and electronic modules. For engineering structures, the use of plastic materials has increased due to the benefits obtained by their low weight, high specific strength and elastic modulus, versatility for design and reduced manufacturing costs. Nowadays thermoplastic structures are designed to play important roles of goods under unfavourable operational and environmental conditions such as cyclic stress / stress, high and low temperatures and rising humidity [11, 14-18]. Polymer-to-polymer joints facilitate design flexibility by exploiting strength properties similar to the parent material. A common example can be seen by mixing thermoplastic matrix 
composites and composites based on thermosetting [11].

For automotive parts where flexibility for design and temperature and chemical resistance are important, polymeric materials such as Polyamide 6 (PA6) are commonly used to substitute metal. In the automotive sector, PA6 applications include door handles, radiator grilles, airbag containers, air intake manifolds, relay boxes, and engine coverings. On the electrical industry, PA6 applications primarily include low-voltage switch gears, circuit breakers, contactors, connectors, wiring and cable safety tubes, and much more for the electronics market [1, 3]. Similarly, polyvinyl chloride (PVC) has biomedical applications, such as medical devices for blood access, and food-product machinery-related parts such as star wheels and guides. Also, PVC is used in many industries in drain waste vent pipe systems and musical instruments. Moreover, PVC shows strong shock absorbance, and is therefore used in golf club heads, vehicle bumper plates, furniture and joinery buffer tops, and luggage and protective cases [4, 19]. This plastic has been criticized in recent years for being produced in a non-environment-friendly process. However, this plastic is still among the most widely used due to its low price. The FW process is challenging when it comes to polymers, as reported in polymeric materials like ABS and high-density polyethylene (HDPE) [19, 20]. The morphology and mechanical properties of these plastics show severe deformations in the vicinity of the weldments.

Numerical code simulating the IFW is a powerful tool for easy tuning of the settings and fast visualization of the process-specific responses to define the weld efficiency [21-26]. Most of the previous studies are limited in the analysing of the more variable parameters of IFW which is quite large and lead to approximate results. A few numerical models were established by assuming a combination of the mechanical and thermal effects. Recently, Numerical models takes into account the coupling of thermal and mechanical effects [19-21, 27-29]. The enormous number of variables leads to massive data output; thus, this requires applying optimization techniques. The aim of optimization technique is to provide optimal or near-optimal solution(s) to the formulated optimization problem. Researchers have developed a large range of techniques for solving optimisation problems, which can be categorized as conventional or nonconventional optimization techniques [30]. The optimization techniques are essential to obtain the optimum parameters for the lowest welding temperature and residual stress in weldment zone. In this context, the new trend of welding process optimization is for soft computing approaches to be the alternative technique for estimating the optimum result of welding parameters, particularly for the temperature and residual stress values in the IFW method. Some computing soft techniques were used by previous works to suggest the optimum conditions of machining problems are the genetic algorithm (GA), simulated annealing (SA), taboo quest (TS), ant colony optimization (ACO), and particle swarm optimization (PSO) $[30,31]$.

In previous research study, Vishnu et. al. combined a Genetic Algorithm with Response Surface Methodology (RSM) to maximize the tensile strength of joining similar medium carbon steels (AISI 1035) by friction welding [32]. Sreenivasan et. al. used the Genetic Algorithm to maximize the Ultimate Tensile Strength (UTS) and Hardness (HD) of the rotary friction welding of Al-SiC composite [33]. Winiczenko et.al. performed an experimental using a genetic algorithm to model the temperature duration during the friction welding cycle of aluminum alloy magnesium alloys [34]. Gupta et.al. developing a second order regression modelling and genetic algorithm-based optimization for joining of dissimilar AA5083-O and AA6063-T6 aluminum alloys by friction stir welding (FSW). The authors suggested parameters are tool rotational speed, welding speed, shoulder diameter and pin diameter for maximizing tensile strength and minimizing grain size [35].

The aim of this work is to obtain the optimum condition of IFW process of dissimilar thermoplastics by GA and get the minimum end welding temperature and Von Mises residual stress. The paper starts with mechanical and thermal properties of PA6 and PVC. Then a simulation model using ANSYS is applied to obtain the best weldment zone. This is followed by developing the regression model of minimum welding temperature and Von Mises residual stresses. Finally, GA was applied to obtain the optimum welding condition and compared with those results found by FE and the regression model.

\section{METHODOLOGY}

In order to fulfil the aim of this study, four steps are implemented to obtain the optimum welding conditions that minimize welding temperature and Von Mises residual stresses values in inertia friction welding, and these are to: 
(1) Study the mechanical and thermal properties of PA6 and PVC for FE model to examine the welding conditions used (rotational speed, axial displacement and weldment time) that contributes to the welding temperature and Von Mises residual stresses results.

(2) Describe the relationship between independent welding variables (welding conditions) and dependent welding variables (welding temperature and residual stresses) by using the regression technique which can define by the $\mathrm{t}$ test.

(3) Find the optimal set value of welding condition to present the minimum objective function (fitness function) by using the GA technique. The GA's objectives lead to minimize the value of welding temperature and Von Mises residual stresses.

(4) Appreciate the solution obtained by GA. The set of welding conditions that give minimum welding temperature and Von Mises residual stresses values produced from GA are compared to the FE and regression model results.

\section{IFW SAMPLE DATA}

\subsection{FE Model}

Modelling of the continuous IFW process with energy-based thermal model is based on sequentially coupled or fully coupled analysis techniques [2]. For simulating the fundamental IFW phenomenon, a detailed coupled non-linear model is needed including the transformation of mechanical stress into thermal energy and plastic deformation. In order to simulate the condition of the IFW process of dissimilar material and to obtain simulation results, changes in the mechanical and thermal properties must be considered and accounted for as input of the FEM. The mechanical and thermal properties of polymeric materials are known to be sensitive to changes in temperature [14]. A previous work by the current authors [36] presented the mechanical and thermal properties of PA6 and PVC at different temperatures starting from room temperature $\left(20^{\circ} \mathrm{C}\right.$ to $100{ }^{\circ} \mathrm{C}$ ). Mechanical and thermal behaviour of PA6 and PVC, including stress-stress response, yield stress, thermal conductivity and specific heat coefficients, are examined at different temperatures.

The FE model began with a sequential analysis in which the modelling began with the calculation of individual sub-steps in the thermal analysis of the complete field followed by the transfer of those results to a parallel structural analysis of the entire field. This was followed by integrating the results of the structural analysis into the thermal analysis in the second step, again transferring the results to the structural model, etc. For each sub-step re-meshing was needed to monitor node and element deformation from one sub-step to another. In this study ANSYS, the commercially available FEA program, was used as a solver and post-processor with numerical calculation capabilities for mechanical / thermal coding [36].

\subsection{Taguchi}

The Taguchi method was used to minimize the number of experimental trials, thereby reducing the time needed, which in effect reduced the cost of finding the necessary information [37, 38]. The aim of use the Taguchi technique is to optimize the welding parameters speed, time, and axial displacement to identify minimum final temperature and Von Mises residual stress [39]. Hence, a smaller-the-better quality characteristic is performed and introduced, as expressed by Eq. 1:

$S / N$ Ratio $\eta=-10 \log \left[\frac{1}{n}\right] \sum_{i=1}^{n} y_{i}^{2}$

where $\mathrm{n}$ is the number of experiments conducted under the given experimental conditions and $\mathrm{y}$ represents the calculated characteristics. Note that the $\mathrm{S} / \mathrm{N}$ or noise ratio as expressed is determined by a smaller-the-better analysis to discover the best estimates for the end temperature and Von Mises residual stresses. The Taguchi method and $\mathrm{L}_{27}$ design were used. Table 1 shows the three parameters and their levels for the design of experiment: rotational speed, time of weldment, and axial displacement.

Table 1: Welding parameters and levels

\begin{tabular}{|c|c|c|c|c|}
\hline Parameters & unit & $\begin{array}{c}\text { level } \\
1\end{array}$ & $\begin{array}{c}\text { level } \\
2\end{array}$ & $\begin{array}{c}\text { level } \\
3\end{array}$ \\
\hline Rotational Speed (v) & $\mathrm{rpm}$ & 500 & 775 & 1200 \\
\hline Time of weldment (t) & $\mathrm{Sec}$ & 4 & 6 & 8 \\
\hline Axial displacement (x) & $\mathrm{mm}$ & 0.045 & 0.09 & 0.18 \\
\hline
\end{tabular}

The order of the trials for the regression procedure was randomized. ANOVA was conducted to examine the input parameters and to show which parameters affect the responses significantly [38].

\subsection{Genetic algorithm (GA)}

One of the optimization algorithms focused on natural selection principles and natural genetics is the Genetic Algorithm (GA), which is more robust and likely to find an optimal global solution. The (GA) begins with a randomly generated population of individuals, each formed by strings (or a chromosome) of the variables of design, representing 
a set of points spanning the search area. The primary solution of the chromosome is evaluated by its fitness function, with respect to the fitness function of the optimization problem. A collection of chromosomes is called population, which is called generation at a given time. Each population size remains constant from one generation to another one.

GA's essential mechanisms are crossover and mutation. Crossover is the way two chromosomes are exchanged for a new offspring. This criteria is important because its assessment of the entire search space. The other characteristic is mutation, is a random adjustment of the chromosome in order to produce a new one and prevent the important information in the new chromosome. Finally, after a

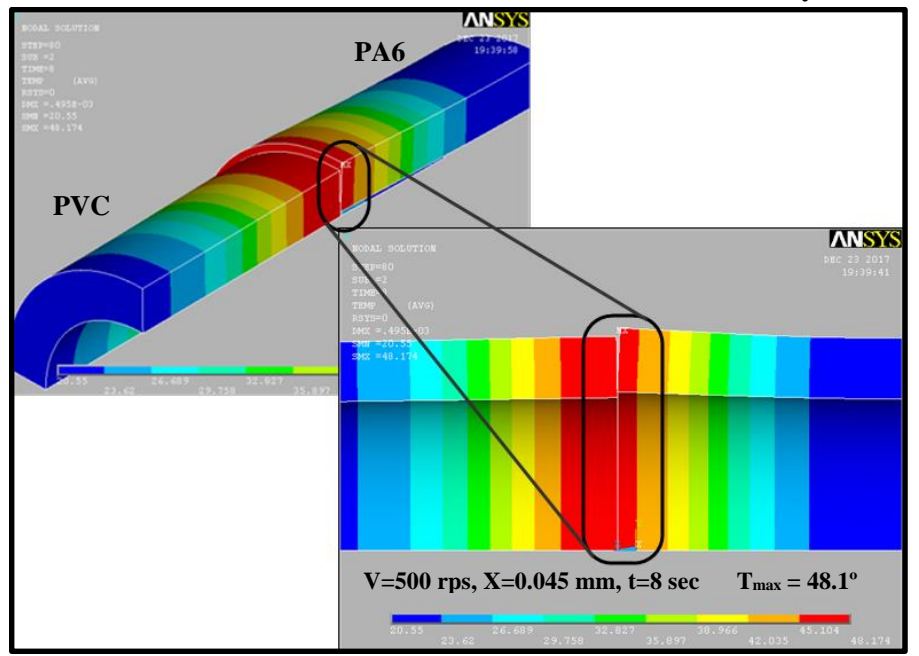

(a)

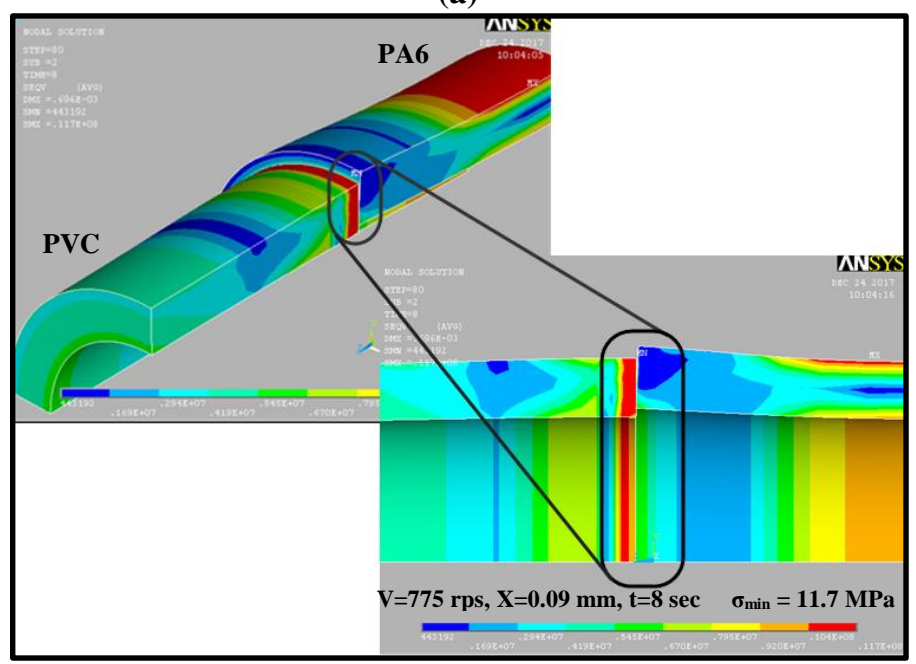

(c) number of iterations of GA, the optimal solution obtained [40-42].

\section{RESULT AND DISCUSSION}

\subsection{FE Results}

For quarter's welded dissimilar polymer hollow cylinder PA6-PVC, homogeneity of the temperature distribution across the pipe length, but it is found that the temperatures at the upper lip of the hollow cylinder during the process are comparatively higher than those at the lower lip. The heat-affected zone (HAZ) was less than $3.5 \mathrm{~mm}$ long around the surface contact of the two sections, as represented in Figure 1.

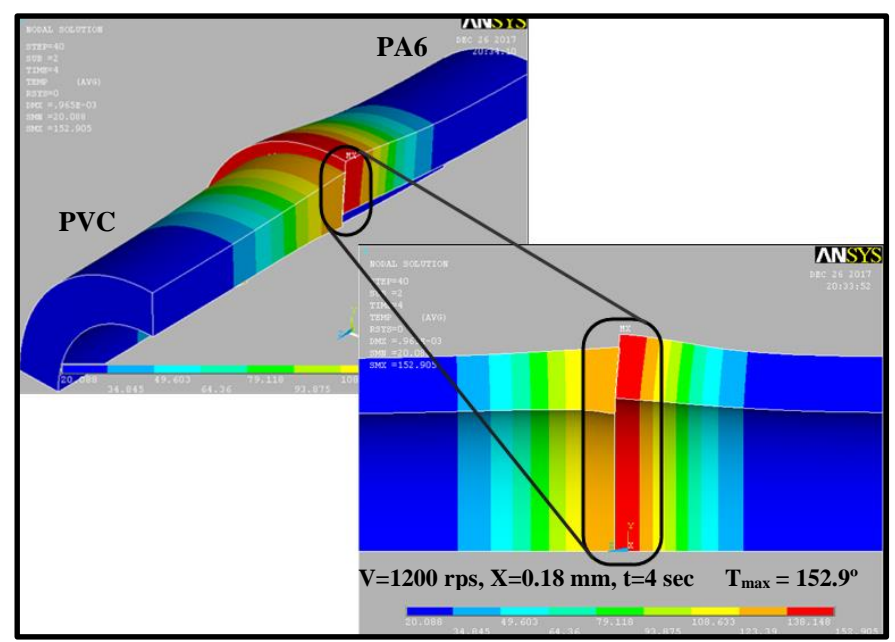

(b)

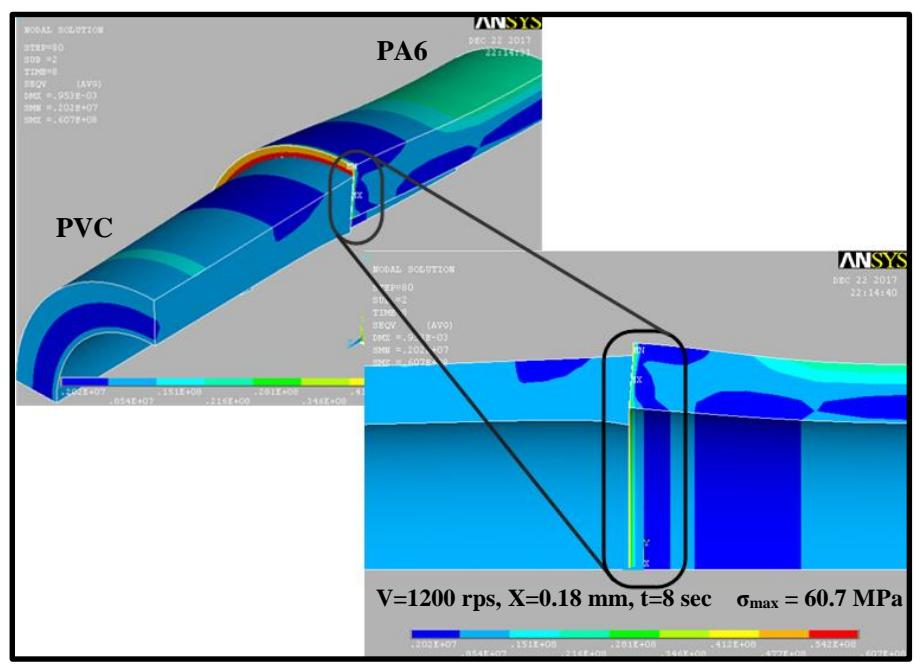

(d)

Figure 1: The deformation shape of PA6-PVC at (a) optimum welding temperature, (b) non-desirable welding temperature, (c) optimum residual stress, and (d) non-desirable residual stress.

The optimum distribution of the welding temperature is defined as the one for which the weld has minimum final welding temperature at the welding contact surface. The optimum weldment temperature distribution for PA6-PVC is shown in Figure 1(a). The final temperature distribution of weld used in 
practice tends to be too high, but it can be moved closer to the optimum which is around $48^{\circ} \mathrm{C}$ for PA6-PVC by modelling the preheating. However, we can see non-desirable, extremely high final temperature distributions of the weld, with high residual stress values in Figure 1(b). The maximum final temperature of the weld is found to be $153{ }^{\circ} \mathrm{C}$ for dissimilar weldment of PA6-PVC cylinders, which does not exceed the melting temperatures of PA6 $\left(225^{\circ} \mathrm{C}\right)$ or PVC $\left(260^{\circ} \mathrm{C}\right)$ respectively.

Similarly, the optimum weld conditions for minimum Von Mises residual stress are shown in Figure 1(c) for welding PA6-PVC with values of 12 MPa. For optimum residual stress, the welding conditions occur at $775 \mathrm{rps}, 0.09 \mathrm{~mm}$ and $8 \mathrm{sec}$. On the other hand, the non-desirable residual stress in weld zone is seriously high-approximately $60 \mathrm{MPa}$ as shown in Figure 1(d). For non-desirable residual stress, the welding conditions occur at $1200 \mathrm{rps}, 0.18$ $\mathrm{mm}$ and $8 \mathrm{sec}$.

Concerning the issue under investigation, FE was performed that dealt with the final temperature and Von Mises residual stress. In the FE model, twenty seven trials were executed that were based on Taguchi's L27 $\left(3^{3}\right)$. The technique is simply a method of finding the optimal setting of the control factors in order to make the product or process insensitive to noise [21]. All the data were tested conditions of the FE trails are given in Table 2.

Table 2: FEA trial results for end weldment temperature and Von Mises residual stress

\begin{tabular}{|c|c|c|c|c|c|}
\hline \multirow[b]{2}{*}{ No } & \multicolumn{3}{|c|}{ Input variables } & \multicolumn{2}{|c|}{ Output } \\
\hline & $\begin{array}{l}\text { Rotational } \\
\text { speed } \\
\text { (r.p.min) } \\
\text { (v) }\end{array}$ & $\begin{array}{l}\text { Time of } \\
\text { weldment } \\
(\mathrm{sec}) \\
(\mathrm{t})\end{array}$ & $\begin{array}{c}\text { Axial } \\
\text { displacement } \\
(\mathrm{mm}) \\
(\mathrm{x})\end{array}$ & $\begin{array}{c}\text { End } \\
\text { Temp. of } \\
\text { Weldment } \\
\left({ }^{0} \mathrm{C}\right) \\
(\mathrm{T})\end{array}$ & $\begin{array}{c}\text { Residual } \\
\text { Stresses } \\
(\mathrm{MPa}) \\
(\sigma)\end{array}$ \\
\hline 1 & 775 & 8 & 0.18 & 89.4 & 24.5 \\
\hline 2 & 500 & 8 & 0.18 & 53.5 & 32 \\
\hline 3 & 1200 & 8 & 0.18 & 127.8 & 60.7 \\
\hline 4 & 775 & 8 & 0.045 & 77.4 & 12.5 \\
\hline 5 & 500 & 8 & 0.045 & 48.1 & 34.3 \\
\hline 6 & 1200 & 8 & 0.045 & 109.4 & 48.5 \\
\hline 7 & 775 & 8 & 0.09 & 80.9 & 11.7 \\
\hline 8 & 500 & 8 & 0.09 & 49.7 & 34.5 \\
\hline 9 & 1200 & 8 & 0.09 & 114.7 & 54.4 \\
\hline 10 & 775 & 6 & 0.18 & 95.3 & 25.4 \\
\hline 11 & 500 & 6 & 0.18 & 55.8 & 30 \\
\hline 12 & 1200 & 6 & 0.18 & 136.1 & 60.6 \\
\hline 13 & 775 & 6 & 0.045 & 82.3 & 12.1 \\
\hline 14 & 500 & 6 & 0.045 & 50.2 & 32.4 \\
\hline 15 & 1200 & 6 & 0.045 & 116.2 & 47.4 \\
\hline 16 & 775 & 6 & 0.09 & 88.1 & 13.5 \\
\hline
\end{tabular}

\begin{tabular}{|c|c|c|c|c|c|}
\hline 17 & 500 & 6 & 0.09 & 51.88 & 32.7 \\
\hline 18 & 1200 & 6 & 0.09 & 121.9 & 52.3 \\
\hline 19 & 775 & 4 & 0.18 & 105.2 & 29.8 \\
\hline 20 & 500 & 4 & 0.18 & 60.2 & 26.1 \\
\hline 21 & 1200 & 4 & 0.18 & 152.9 & 60.6 \\
\hline 22 & 775 & 4 & 0.045 & 90.7 & 15.5 \\
\hline 23 & 500 & 4 & 0.045 & 54.1 & 28.3 \\
\hline 24 & 1200 & 4 & 0.045 & 129.3 & 45 \\
\hline 25 & 775 & 4 & 0.09 & 95.1 & 17.1 \\
\hline 26 & 500 & 4 & 0.09 & 55.9 & 28.6 \\
\hline 27 & 1200 & 4 & 0.09 & 136.4 & 50.7 \\
\hline & & Min. value & 48.1 & 11.7 \\
\cline { 4 - 6 } & Max. value & 152.9 & 60.7 \\
\cline { 4 - 6 } & & $\begin{array}{c}\text { Average } \\
\text { value }\end{array}$ & 100.5 & 36.2 \\
\cline { 5 - 6 } & & & \\
\end{tabular}

\subsection{Regression model}

\subsubsection{Regression model for temperature}

The regression model for end weldment temperature, based on the data for the FEA results given in Table 2 , is given in Eq. (2). The analysis of variance (ANOVA) and values of coefficients for the regression model parameters of end weldment temperature are given in Tables (3-4), respectively. The analyses are obtained by using the statistical software MINITAB. For a model with three factors namely rotation speed, axial displacement, and welding time; the sequential sum of squares for axial displacement shows how much of the remaining variation is explained by axial displacement, given that rotation speed is already included in the model. The regression method is repeated by entering the variables to obtain a new set of factors in a particular order. ANOVA is conducted to analyze design parameters and show which parameters affect the performance parameters significantly as shown in Table3. The ratio of variance due to individual factor and variance due to error term is known as F-value. Usually, when $F>4$, it means that the difference in the design parameter has significant influence on the quality characteristic [43].

Table 3: Analysis of variance for end of temperature

\begin{tabular}{|c|c|c|c|c|c|}
\hline Source & DF & Adj SS & Adj MS & $\begin{array}{c}\text { F- } \\
\text { Value }\end{array}$ & $\begin{array}{c}\text { P- } \\
\text { Value }\end{array}$ \\
\hline Regression & 3 & 26040.3 & 8680.1 & 282.4 & 0.0 \\
\hline V & 1 & 24300.5 & 24300.5 & 790.62 & 0 \\
\hline t & 1 & 923.1 & 923.1 & 30.03 & 0 \\
\hline x & 1 & 816.7 & 816.7 & 26.57 & 0 \\
\hline Error & 23 & 706.9 & 30.7 & & \\
\hline Total & 26 & 26747.2 & & & \\
\hline
\end{tabular}


The F-value shows that rotational speed has the most significant effect on end weldment temperature. Then time of weldment and axial displacement came in second and third order effect of weldment temperature respectively.

Table 4: Coefficients values for end weldment temperature

\begin{tabular}{|c|c|c|c|c|c|}
\hline Term & Coef & SE coef & T-value & $\begin{array}{c}\text { P- } \\
\text { value }\end{array}$ & VIF \\
\hline Constant & 15.19 & 5.46 & 2.78 & 0.011 & \\
\hline $\mathrm{V}$ & 0.10418 & 0.00371 & 28.12 & 0.000 & 1.00 \\
\hline $\mathrm{t}$ & -3.581 & 0.653 & -5.48 & 0.000 & 1.00 \\
\hline $\mathrm{x}$ & 98 & 19 & 5.15 & 0.000 & 1.00 \\
\hline
\end{tabular}

By passing coefficients values for weldment end temperature from Table 4, the linear regression model equation of end temperature of weldment can be written as follows:

End Temperature of Weldment $=15.19+0.10418 v$ $-3.581 t+98 x$

Equation 2 is applied to calculate the predicted value of end weldment temperature, and the results are summarized in Figure 2.

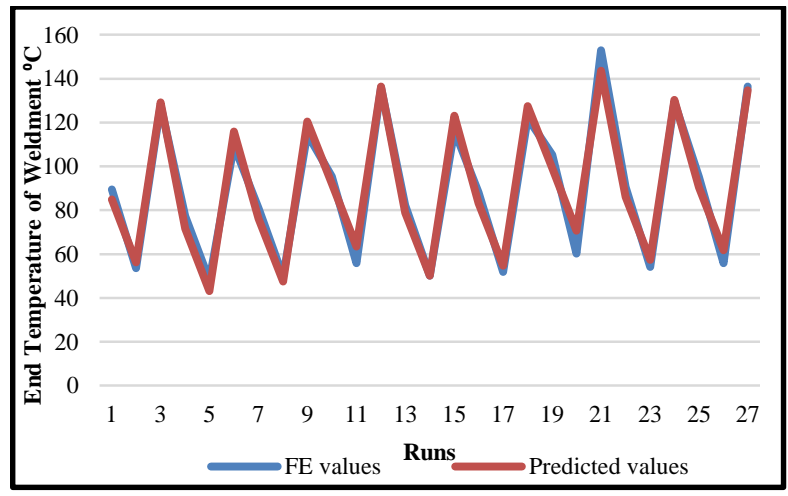

Figure 2: FEA results verse predicted for end temperature of weldment

The predicted results of regression model show good agreement with FE results of weldment end temperature.

\subsubsection{Regression model for residual stress}

Similarity, based on the FE results given in Table 2, non-linear regression model for Von Mises residual stress is given in Eq. 3. The ANOVA and coefficients values for the regression model of Von Mises residual stress are given in Tables (5-6), respectively.
Table 5: Analysis of variance for Von Mises residual stress

\begin{tabular}{|c|ccccccc|}
\hline \multicolumn{7}{|c|}{ Analysis of Variance of residual stress } \\
\hline Source & DF & Seq SS & Cont.\% & Adj SS & Adj MS & F- & P- \\
Model & 9 & 6258.78 & 96.49 & 6258.78 & 695.42 & 52 & 0 \\
Linear & 3 & 3283.84 & 50.63 & 2699.29 & 899.76 & 67.28 & 0 \\
$v$ & 1 & 2954.4 & 45.55 & 2375.05 & 2375.05 & 177.59 & 0 \\
$t$ & 1 & 7.22 & 0.11 & 5.13 & 5.13 & 0.38 & 0.544 \\
$x$ & 1 & 322.22 & 4.97 & 338.8 & 338.8 & 25.33 & 0 \\
Square & 3 & 2801.27 & 43.19 & 2801.27 & 933.76 & 69.82 & 0 \\
$v * v$ & 1 & 2799.36 & 43.16 & 2799.36 & 2799.36 & 209.32 & 0 \\
$t * t$ & 1 & 0.07 & 0.00 & 0.07 & 0.07 & 0.01 & 0.942 \\
$x * x$ & 1 & 1.83 & 0.03 & 1.83 & 1.83 & 0.14 & 0.716 \\
Way & & & & & & & \\
Interaction & 3 & 173.67 & 2.68 & 173.67 & 57.89 & 4.33 & 0.019 \\
$v * t$ & 1 & 3.74 & 0.06 & 3.74 & 3.74 & 0.28 & 0.604 \\
$v * x$ & 1 & 167.1 & 2.58 & 167.1 & 167.1 & 12.49 & 0.003 \\
$t * x$ & 1 & 2.83 & 0.04 & 2.83 & 2.83 & 0.21 & 0.651 \\
Error & 17 & 227.36 & 3.51 & 227.36 & 13.37 & & \\
Total & 26 & 6486.14 & 100 & & & & \\
\hline
\end{tabular}

Table 6: Coefficients values for Von Mises residual stress

\begin{tabular}{|c|c|c|c|c|c|c|}
\hline Term & Effect & Coef & $\begin{array}{c}\text { SE } \\
\text { Coef }\end{array}$ & $\begin{array}{c}\mathrm{T}- \\
\text { Value }\end{array}$ & $\begin{array}{c}\text { P- } \\
\text { Value }\end{array}$ & VIF \\
\hline Constant & & 19.32 & 2.04 & 9.47 & 0.000 & \\
\hline$v$ & 23.175 & 11.587 & 0.87 & 13.33 & 0.000 & 1.03 \\
\hline$t$ & 1.082 & 0.541 & 0.873 & 0.62 & 0.544 & 1.03 \\
\hline$x$ & 8.708 & 4.354 & 0.865 & 5.03 & 0.000 & 1.04 \\
\hline$v * v$ & 45.62 & 22.81 & 1.58 & 14.47 & 0.000 & 1.02 \\
\hline$t * t$ & 0.22 & 0.11 & 1.49 & 0.07 & 0.942 & 1.00 \\
\hline$x * x$ & 1.27 & 0.63 & 1.71 & 0.37 & 0.716 & 1.04 \\
\hline$v * t$ & -1.11 & -0.55 & 1.05 & -0.53 & 0.604 & 1.01 \\
\hline$v * x$ & 7.27 & 3.64 & 1.03 & 3.53 & 0.003 & 1.03 \\
\hline$t * x$ & -0.95 & -0.48 & 1.04 & -0.46 & 0.651 & 1.02 \\
\hline
\end{tabular}

By moving the coefficients values for residual stress from Table 6, the non-linear regression model equation of residual stress can be written as follows:

Residual stress $(\mathbf{M P a})=127.9-0.2960 \mathrm{v}+1.01 \mathrm{t}-$ $76 \mathrm{x}+0.000186 \mathrm{v}^{2}+0.028 \mathrm{t}^{2}+139 \mathrm{x}^{2}-0.00079 \mathrm{vt}$ $+0.1539 \mathrm{vx}-3.53 \mathrm{tx}$

Consequently, FE results (given in Table 2) compared to the predicted Von Mises residual stress values of the regression model (Eq. 3) as shown in Figure 3. 


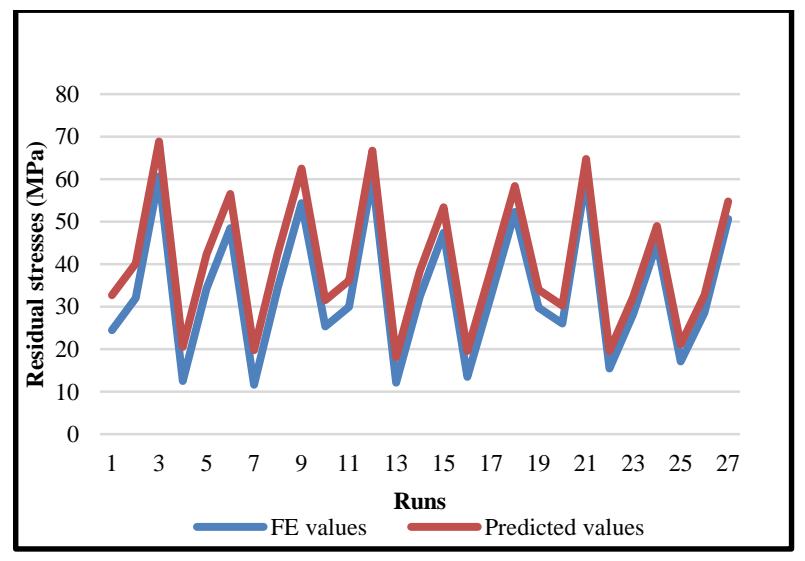

Figure 3: FEA results verse predicted for residual stress

The predicted values according to non-linear regression of residual stress show slight agreement with FE results.

\subsection{Genetic algorithm optimization}

\subsubsection{GA for end weldment temperature}

In current study, the aim of the optimization process is to determine the optimum set of the welding independent variables which contribute to the lowest possible minimum end welding temperature. To formulate the GA algorithm, the minimization of end weldment temperature proposed in Eq. 2 is taken as the objective function and subjected to the welding boundary condition values given by Eq. 4, 5, and 6 . The limitations of welding boundary condition given in Table 1 are formulated as follows:

$$
\begin{aligned}
& 500 \leq \mathrm{v} \leq 1200 \\
& 4 \leq \mathrm{t} \leq 8 \\
& 0.045 \leq \mathrm{x} \leq 0.18
\end{aligned}
$$

For GA optimization technique, the end weldment temperature value of the FE result, regression techniques, and GA technique (from Figure 4) are 48.1, 43.042 and 43.042 respectively; summarized in Table 7.

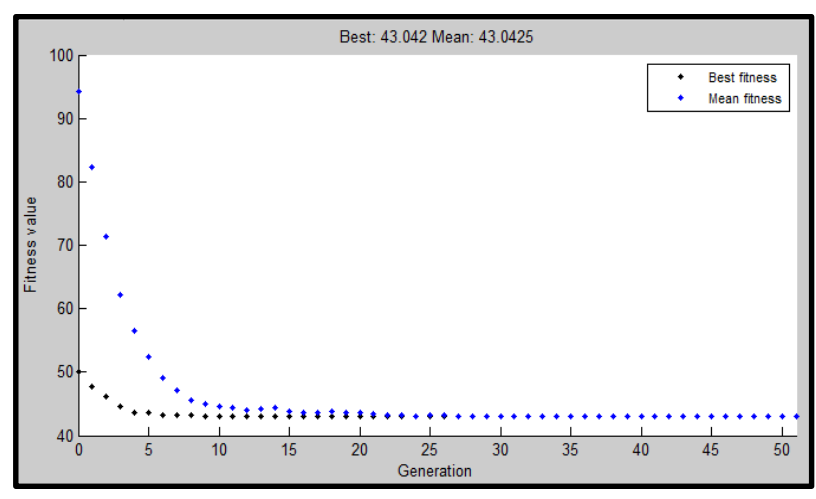

Figure 4: Plot function of the best fitness of end weldment temperature

Table 7: Comparison the optimal welding condition results for end weldment temperature

\begin{tabular}{|c|c|c|c|c|}
\hline \multirow{2}{*}{ Technique } & \multirow{2}{*}{$\begin{array}{c}\text { Optimal end } \\
\text { weldment } \\
\text { temperature }\end{array}$} & $\begin{array}{c}\text { Rotational } \\
\text { speed }\end{array}$ & $\begin{array}{c}\text { Weldment } \\
\text { time }\end{array}$ & $\begin{array}{c}\text { Axial } \\
\text { displacement }\end{array}$ \\
\cline { 3 - 5 } & 48.1 & 500 & 8 & 0.045 \\
\hline FE model & 43.042 & 500 & 8 & 0.045 \\
\hline $\begin{array}{c}\text { Regression } \\
\text { model }\end{array}$ & 43.042 & 500 & 8 & 0.045 \\
\hline GA & & &
\end{tabular}

It can be concluded that there are similar between the regression model and the GA technique of the minimum average result of the end welding temperature than results of FE.

\subsubsection{GA solution of residual stresses}

Similarity, the optimum set of the welding independent variables which contribute to the lowest possible of Von Mises residual stress. The minimization of Von Mises residual stress proposed in Eq. 3 is taken as the objective function and subjected to the welding boundary condition values given by Eq. 4, 5, and 6 .

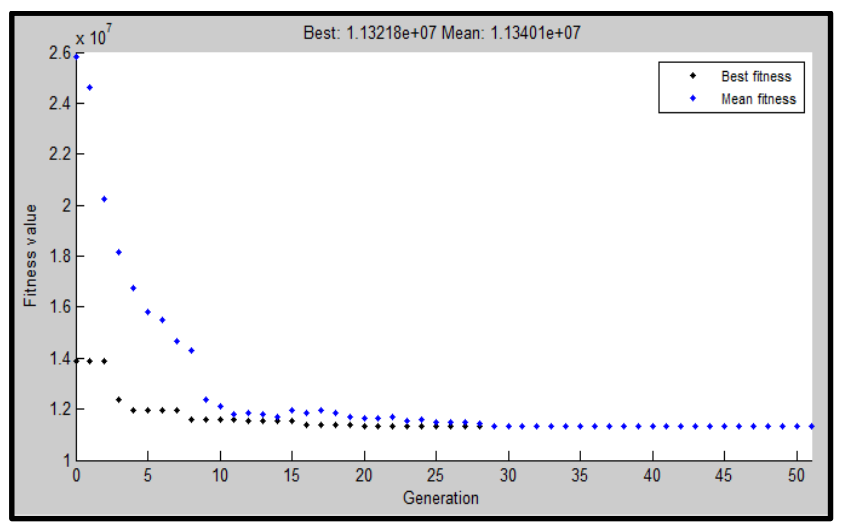

Figure 5: Plot function of the best fitness of Von Mises residual stress 
For GA optimization technique, the Von Mises residual stress value of the FE result, regression techniques, and GA technique (from Figure 5) are $11.7,18.15$ and 11.3 respectively; summarized in Table 10.

Table 8: Comparison the optimal welding condition results for Von Mises residual stress

\begin{tabular}{|c|c|c|c|c|}
\hline \multirow[b]{2}{*}{ Technique } & \multirow[b]{2}{*}{$\begin{array}{c}\text { Optimal } \\
\text { residual stress }\end{array}$} & \multicolumn{3}{|c|}{ Optimal welding condition } \\
\hline & & $\begin{array}{l}\text { Rotational } \\
\text { speed }\end{array}$ & $\begin{array}{l}\text { Weldment } \\
\text { time }\end{array}$ & $\begin{array}{c}\text { Axial } \\
\text { displace } \\
\text { ment }\end{array}$ \\
\hline FE model & 11.7 & 775 & 8 & 0.09 \\
\hline $\begin{array}{l}\text { Regression } \\
\text { model }\end{array}$ & 18.15 & 775 & 6 & 0.045 \\
\hline GA & 11.3 & 775 & 4 & 0.045 \\
\hline
\end{tabular}

The minimum average result of the residual stress value estimated by GA technique has minimum value than those obtained by $\mathrm{FE}$ and regression model.

\section{CONCLUSION}

The present study estimates the optimal solutions of friction welding of dissimilar hollow cylinder thermoplastics PA6-PVC by applied the GA technique. The GA technique leads to minimize the end weldment temperature and Von Mises residual stress value. The welding optimization problem is involving welding parameters namely rotational speed, welding time and axial displacement.

To get the final temperature and Von Mises residual stresses for the weldment, FEA simulation code of FW processes were used [36]. The numerical analysis is sufficient to predict the deformations through the IFW process. The successful experiment measuring the mechanical properties of the nonlinear material is the key issue for FE's success in capturing the phenomenon [36].

After that, it has been discovered that the regression technique used to model the relation between welding condition and weldment end temperature which is linear relationship. On the contrary, a non-linear relationship was found in the relation between welding condition and Von Mises residual stress. In both regression model of end weldment temperature and Von Mises residual stress, there are good agreement between predicted and $\mathrm{FE}$ results. The minimum and maximum error percentage between $\mathrm{FE}$ and predicted results of welding temperature are $0.08 \%$ and $17.26 \%$ respectively. On the other hand, the error percentages of Von Mises residual stress start from $0.34 \%$ to $26.15 \%$.
Therefore, these relations of end weldment temperature and Von Mises residual stress have been selected to be the fitness function equation for the GA optimization solution. The GA technique has the minimum average result of the end weldment temperature and Von Mises residual stress values compared with those obtained by FE and regression model.

\section{Credit Authorship Contribution Statement}

Samar Elsanabary: Methodology, Investigation, Formal analysis, Writing - Original Draft Hanan Kouta: Conceptualization, Methodology, Writing - Review editing.

\section{Declaration of Competing Interest}

The authors declare that they have no known competing financial interests or personal relationships that could have appeared to influence the work reported in this paper.

\section{References}

[1] Kumar, R., Singh,R., Ahuja, I.P.S., Amendola, A., Penna, R. "Friction welding for the manufacturing of PA6 and ABS structures reinforced with Fe particles," Composites Part B, Vol.132, 2018, pp: 244257, DOI 10.1016/j.compositesb.2017.08.018

[2] El-Hadek, M.A. "Numerical Simulation of the Inertia Friction Welding Process of Dissimilar Materials," Metallurgical and Materials Transactions B, ISSN 1073-5615, Vol. 45, 2014, pp: 2346-2356, DOI 10.1007/s11663014-0148-2

[3] Senthil, S.K.; Srinivasan, K.; Narayanan, S.; Joseph Raj, A.N. "Prediction of Tensile Strength in Friction Welding Joins Made of SA213 Tube to SA387 Tube Plate through Optimization Techniques" Materials, Vol. 12, 2019, 4079, DOI 10.3390/ma12244079

[4] Kim, Y.S.; Kim, J.K.; Na, S.J.; Jeon, E.S. "Experimental Analysis on the Application of Polymer Matrix Composites Containing A12O3 for Automotive Lamp Reflector" Appl. Sci., Vol. 9, 2019, 4525, DOI 10.3390/app9214525

[5] Wang, Y.K.; Tsai, F.C.; Ma, C.C.; Wang, M. L.; Kuo, S.-W. "Using Methacryl-Polyhedral Oligomeric Silsesquioxane as the Thermal Stabilizer and Plasticizer in Poly (vinyl chloride) Nanocomposites" Polymers, Vol.11, 2019, 1711, DOI10.3390/polym11101711

[6] Zhao, Y.; Luo, Y.; Zhang, Z.; Zhang, H.; Guo, X.; Wang, S.; Cui, H.; Zhang, Y. 
"Fractal Dimension Characterization of Joint Surface Morphology on Dissimilar Friction Stir Lap Welding of Al/Mg:" Materials Vol. 12, 2019, 3941, DOI 10.3390/ma12233941

[7] Chen, Y.; Li, H.; Wang, X.; Ding, H.; Zhang, F. A "Comparative Investigation on Conventional and Stationary Shoulder Friction Stir Welding of Al-7075 Butt-Lap Structure" Metals, Vol. 9, 2019, 1264, DOI 10.3390/met9121264

[8] Li, H.; Gao, J.; Li, Q. "Fatigue of Friction Stir Welded Aluminum Alloy Joints: A Review" Appl. Sci., Vol.8, 2018, 2626, DOI 10.3390/app8122626

[9] Kang, S.; Kim, J.; Jang, Y.; Lee, K. "Welding Deformation Analysis, Using an Inherent Strain Method for Friction Stir Welded Electric Vehicle Aluminum Battery Housing, Considering Productivity" Appl. Sci., Vol. 9, 2019, 3848, DOI 10.3390/app9183848

[10] Meyghani, B.; Awang, M.B.; Emamian, S.S.; Mohd Nor, M.K.B.; Pedapati, S.R. "A Comparison of Different Finite Element Methods in the Thermal Analysis of Friction Stir Welding (FSW)" Metals, Vol. 7, 2017, 450, DOI 10.3390/met7100450

[11] MERS Paul Kah, Raimo Suoranta, Jukka Martikainen, Carl M, "Techniques for joining dissimilar materials: metals and polymers," Rev. Adv. Mater. Sci. Vol. 36(1), 2014

[12] M. Akbari and R.A. Behnagh: Metall. Mater. Trans. B, vol. 43B, 2012, pp. 1177-86. DOI: 10.1007/s11663-012-9682-y.

[13] Y. Zhu, Y. Guo, and L. Yang: Metall. Mater. Trans. B, vol. 44B, 2013, pp. 396-405. DOI: 10.1007/s11663-013-9795-y.

[14] Wang, Z., Zhou, Y., and Mallick, P. K. "Effects of Temperature and Strain Rate on the Tensile Behavior of Short Fiber Reinforced Polyamide-6," Polymer Composites, Vol. 23, No. 5, 2002, pp: 858871, DOI 10.1002/pc. 10484

[15] Jia, Nanying and Kagan, Val. "Mechanical Performance of Polyamides with Influence of Moisture and Temperature - Accurate Evaluation and Better Understanding," Plastics Failure Analysis and Prevention, 2001, pp.95-104, DOI: 10.1016/B978188420792-1.50014-7

[16] Celestine, AD.N. and Zhu, S.S. "Effect of Temperature and Moisture on the Mechanical Properties of Fiber Reinforced Nylon 6 Composites," In: Antoun B. et al. (eds) Challenges in Mechanics of Time Dependent Materials, Volume 2, 2017, pp:109-118. Conference of Proceedings of the Society for
Experimental Mechanics Series. Springer, Cham, DOI: 10.1007/978-3-319-41543-714

[17] Tae-Kyu Kang, Yang Kim, Won-Jei Cho \& Chang-Sik Ha "Effects of Amorphous Nylon on the Properties of Nylon 6," Polymer Testing 16, Vol.3, 1997, pp: 91-40, DOI 10.1016/S0142-9418(96)00059-1

[18] Elkaseer, A.; Mueller, T.; Azcarate, S.; Philipp-Pichler, M.; Wilfinger, T.; Wittner, W.; Prantl, M.; Sampaio, D.; Hagenmeyer, V.; Scholz, S. "Replication of Over molded Orthopedic Implants with a Functionalized Thin Layer of Biodegradable Polymer" Polymers 10, 2018, 707, DOI 10.3390/polym 10070707

[19] Gao, J., Li, C., Shilpakar, U. and Shen, Y., "Improvements of mechanical properties in dissimilar joints of HDPE and ABS via carbon nanotubes during friction stir welding process" Materials \& Design, 86, 2015, pp. 289-296, DOI 10.1016/j.matdes.2015.07.095

[20] Gao, J., Li, C., Shilpakar, U. and Shen, Y., "Microstructure and tensile properties of dissimilar submerged friction stir welds between HDPE and ABS sheets" The International Journal of Advanced Manufacturing Technology, 87(1-4), 2016, pp.919-927, DOI 10.1007/s00170-016-8539-y

[21] El-Hadek, M.A., "Sequential Transient Numerical Simulation of Inertia Friction Welding Process" International Journal for Computational Methods in Engineering Science and Mechanics, 10(3), 2009, pp.224230, DOI 10.1080/15502280902795086

[22] Elkaseer, A.; Abdelaziz, A.; Saber, M.; Nassef, A. "FEM-Based Study of Precision Hard Turning of Stainless Steel 316L" Materials, 12, 2522, 2019, DOI $10.3390 / \mathrm{ma} 12162522$

[23] Cascón, I.; Sarasua, J.A.; Elkaseer, A. "Tailored Chip Breaker Development for Polycrystalline Diamond Inserts: FEM-Based Design and Validation" Appl. Sci. 9, 2019, 4117, DOI 10.3390/app9194117

[24] Jedrasiak, P.; Shercliff, H.R. "Finite element analysis of heat generation in dissimilar alloy ultrasonic welding" 2018, JMADE, DOI:10.1016/ j.matdes.2018.07.041

[25] Jedrasiak, P.; Shercliff, H.R.; McAndrew, A.R.; Colegrove, P.A. "Thermal modelling of linear friction welding" Materials and Design, Volume 156, 2018, pp:362-369, DOI 10.1016/j.matdes.2018.06.043

[26] Jedrasiak, P.; Shercliff, H.R. "Small strain finite element modelling of friction stir spot welding of $\mathrm{Al}$ and $\mathrm{Mg}$ alloys" Journal of 
Materials Processing Tech., Volume 263, 2019, pp:207-222,

DOI 10.1016/j.jmatprotec.2018.07.031

[27] C. J. Dawes, "Micro-friction welding aluminum studs to mild steel plates" Journal of Metal Construction, 9 (5), 1977, pp 196197.

[28] Fu, L., and Duan, L. Y. "The coupled deformation and heat flow analysis by finite element method during friction welding" Welding Journal, 77(5), 1998, pp. 202-207.

[29] C. J. Bennett, T. H. Hyde, and E. J. Williams, "Modelling and simulation of the inertia friction welding of shafts" Journal of Materials: Design and Applications, Vol. 221(4), 2007, pp. 275-284, DOI 10.1243/14644207JMDA154

[30] Mukherjee I, Kumar Ray P,"A review of optimization techniques in metal cutting processes," Computers \& Industrial Engineering, vol. 50, 2006, pp:15-34, DOI 10.1016/j.cie.2005.10.001

[31] Azlan Mohd Zain a, Habibollah Haron a, Safian Sharif," Application of GA to optimize cutting conditions for minimizing surface roughness in end milling machining process," Expert Systems with Applications 37 , 2010, pp:4650-4659,

DOI 10.1016/j.eswa.2009.12.043

[32] Vishnu, P.S.; Sujith J. "Optimization of Friction Welding Parameters for Joining Medium Carbon Steels using Response Surface Methodology" International Journal of Engineering Research \& Technology (IJERT), ISSN: 2278-0181, Volume 3 (10), 2014,pp:338-345.

[33] Sreenivasan, K.S.; Satish Kumar, S.; Katiravan, J. "Genetic algorithm based optimization of friction welding process parameters on AA7075-SiC composite" Engineering Science and Technology, an International Journal, Volume 22, 2019, pp:1136-1148,

DOI 10.1016/j.jestch.2019.02.010

[34] Winiczenko, R.; Sibicki, A.; Skoczylas, P.; and Trajer, J. "A genetic algorithm modelling of temperature distributions in the AZ31B magnesium alloys with 7075 aluminium alloy friction welded joints" E3S Web of Conferences, Volume 132, 2019, pp:1-10, DOI:10.1051/e3sconf/201913201029

[35] Gupta, S.K., Pandey, K.N. and Kumar, R. 'Experimental modelling and genetic algorithm-based optimisation of friction stir welding process parameters for joining of dissimilar AA5083-O and AA6063-T6 aluminum alloys' Int. J. Materials and Product Technology, Vol. 56, No. 3, 2018, pp.253-270,

DOI 10.1504/IJMPT.2018.090818

[36] H., Kouta, S., Elsanabary, M., ElHadek, A., Elkaseer, "FE Simulation of Inertia Friction Welding of Similar PVC-PVC and PA6- PA6 Hollow Cylinders for Process Optimization" SYLWAN, Volume 1, Issue164, 2020, pp:407-428

[37] Lavish, Sh.; Prakash, Sh.; Nitin, Sh. "Optimization of cutting parameters for surface roughness in turning of alloy steel EN47" International journal of advanced research \& Technology, Volume 2(4), 2016, pp:14-18, DOI 10.13140/RG.2.2.23103.56484

[38] Srinivas, A.; Venkatesh, Y.D. "Application Of Taguchi Method For Optimization Of Process Parameters In Improving The Surface Roughness Of Lathe Facing Operation" International refereed journal of engineering and science, Volume 1(3), 2012, pp:13-19.

[39] Doddapattar, N.B.; Puneeth, S. "Optimization of cutting parameters using signal-to-noise ratio for turning aluminum alloy A17050" International journal of ignited minds, Volume 1, Issue 9, 2014, pp:1-6.

[40] Bhaskara Reddya, S.V., Shunmugama, M.S., Narendranb, T.T. "Optimal sub-division of the depth of cut to achieve minimum production cost in multi-pass turning using a genetic algorithm," Journal of Materials Processing Technology, 79, 1998, pp. 101108, DOI 10.1016/S0924-0136(97)00400-7

[41] Doriana, M. D, Addona , Roberto, T. "Genetic algorithm-based optimization of cutting parameters in turning processes," Forty Sixth CIRP Conference on Manufacturing Systems, Procedia CIRP, 7, 2013, pp.323 - 328,

DOI 10.1016/j.procir.2013.05.055

[42] Sardiñas, R.Q., Santana, M.R., and Brindis, E.A. "Genetic algorithm-based multiobjective optimization of cutting parameters in turning processes" Engineering Applications of Artificial Intelligence, 19, 2006, pp:127-133,

DOI 10.1016/j.engappai.2005.06.007

[43] W.H.Yang, Y.S.Tarng," Design optimization of cutting parameters for turning operations based on the Taguchi method" journal of materials processing technology 84, 1998, pp. 122-129, DOI10.1016/S0924-0136(98)00079$\mathrm{X}$ 